CORPOS MAIS: Uma proposta de pesquisa artística e educacional com normalistas do Instituto de Educação CIEP 179

BODIES MORE: A proposal of artistic and educational research with normalists of the Instituto de Educação CIEP 179

\author{
Massuel dos Reis Bernardi \\ massuel@gmail.com \\ UFRJ, UFU, PUC-Rio
}

\begin{abstract}
Resumo:
Como parte da pesquisa de toda a pós-graduação do autor, este artigo objetiva apresentar uma proposta de trabalho de um professor de dança nas disciplinas de Arte e Laboratório ArteEducação (LAE) com normalistas do Instituto de Educação CIEP 179 (SEEDUC/RJ) de São João de Meriti-RJ. Através de uma Pesquisa Narrativa (CLANDININ E CONELLY, 2011), apresentam-se os diálogos entre os corpos mais cada linguagem artística previstas pelos PCN-Arte (2000): corpos mais artes visuais; corpos mais música; corpos mais teatro; e corpos mais dança. Dessa forma, a cada bimestre letivo, os diálogos entre os corpos nos processos de criação artística apresentam resultados na exploração de possibilidades pedagógicas quando os/as normalistas estiverem exercendo a profissão docente.
\end{abstract}

Palavras-chave: Corpos mais, normalistas, ensino de artes cênicas.

\title{
Abstract:
}

As part of the research of the entire post-graduation of the author, this article aims to present a proposal of work of a dance teacher in the Art and Education Art-Education (LAE) disciplines with the Instituto de Educação CIEP 179 (SEEDUC / RJ) of São João de Meriti-RJ. Through a Narrative Research (CLANDININ AND CONELLY, 2011), the dialogues between the bodies and each artistic language provided by the PCN-Arte (2000) are presented: bodies more visual arts; bodies more music; bodies more theater; and bodies more dance. Thus, each academic bimester, the dialogues between the bodies in the processes of artistic creation present results in the exploration of pedagogical possibilities when the normalists are exercising the teaching profession.

Keywords: Bodies more, normalist, scene arts education.

Desde 2015 desenvolvo uma proposta de trabalho intitulada corpos mais, que consiste na prática corporal em diálogo com as quatro linguagens artísticas previstas pelos PCN-Arte (2000). Tratam-se de processos artísticos e pedagógicos que se edificam nos corpos dos/as estudantes e buscam a construção de um corpo cênico (FABIÃO, 2010). Ao entrelaçar os conceitos da pesquisa, traço um caminho entre "O ensino e o conhecimento do professor expressos em histórias sociais e 
individuais corporificadas [...] sob o título de pesquisa narrativa" (CLANDININ E CONNELLY, 2011, p. 32).

O Instituto de Educação (IE) Centro Integrado de Educação Pública (CIEP) 179 - Professor Cláudio Gama é uma escola de Ensino Médio vinculada à Secretaria de Estado de Educação do Rio de Janeiro (SEEDUC) localizada em São João de Meriti, na Baixada Fluminense, inscrita na modalidade Curso Normal. Isto é, segundo as diretrizes do ensino nos Institutos de Educação (LDB 9.394/96) e da resolução 02/2015 do Ministério da Educação (MEC) os/as alunos/as concluintes saem com o diploma de professor/a habilitado para lecionar na Educação Infantil, Ensino Fundamental I (até o 5o ano) e Educação de Jovens e Adultos.

O quadro docente da escola é formado por professores/as da rede estadual, em grande quantidade de professores/as licenciados/as em Pedagogia que lecionam disciplinas pedagógicas ${ }^{1}$. As disciplinas tratadas no estudo se referem à Arte no primeiro e terceiro anos e Laboratório ArteEducação (LAE) no segundo ano do Ensino Médio com carga horária de 1h40min e 50min semanais, respectivamente. O concurso prestado para a admissão de professores/as de Arte e LAE na SEEDUC/RJ aceita quaisquer das quatro formações artísticas previstas nos PCN-Arte (2000). No IE CIEP 179, há três professores/as da disciplina de Arte: uma com formação em artes visuais; um com formação em dança; e outra com formação em teatro. E, por sorte, há um professor de disciplinas pedagógicas que possui formação musical no Conservatório Brasileiro de Música, o que proporciona aos/as alunos/as um espaço privilegiado de contato com as artes.

Os/as estudantes têm, em maioria, idades entre 14 e 18 anos. Há um pequeno número de alunos/as mais velhos/as de até 50 anos, inclusive reingressantes no Ensino Médio, justamente em busca da formação no Curso Normal.

As relações entre diferentes agentes envolvidos tornam o IE CIEP 179 um lugar que caracteriza nas palavras da diretora geral "uma grande família”. Essa “família IE CIEP 179" vislumbra uma relação afetiva e significativa de envolvimento bastante profundo de alunos/as, professores/as, equipe e comunidade escolar. Uma vez que estão em consonância com o que é vivenciado lá dentro, as relações da profissão docente amadurecem com o passar dos anos, edificam as potencialidades dos corpos e estabelecem redes de produção de subjetividade.

\footnotetext{
${ }^{1}$ Disciplinas da grade curricular exclusivas do Curso Normal voltadas para a formação docente.
} 


\section{Corpos mais}

Como licenciado em dança, as possibilidades de trabalho artístico vêm se estabelecendo a partir das potências dos corpos. Percebo que os corpos carregam em si capacidades poéticas expansíveis no trabalho artístico. Sob essa ótica, pode-se afirmar que meu trabalho é um trabalho de dança. Chamo, portanto, de corpos mais as somas vindas do corpo como ponto de partida, fundamento das reflexões. Não é possível tratar de corpo no singular, pois as bases do estudo são a educação e as artes, além das interlocuções estabelecidas com os múltiplos corpos que habitam - IE CIEP 179. Desse modo, é preciso falar de um lugar múltiplo, habitado por múltiplos atravessamentos. Por isso, uso do plural: corpos mais.

Com base nesses aspectos, comecei a me indagar: se a aula é um lugar de exposição, de visibilidade para o/a professor/a e/ou para o/a aluno/a, como se dá a experiência artísticocorporal para estudantes/futuros/as professores/as? Foi então que comecei buscar ressignificar diversos fatores como o espaço, objetos, sonoridades, ambientes, relações, e os próprios corpos. Vi que essa ressignificação poderia sugerir propostas não só para a construção de um corpo cênico que vá fazer diferença para o/a estudante/futuro/a professor/a, mas poderia refletir em suas próprias práticas pedagógicas. As somas, que tratam os corpos mais, seguiram, portanto, no sentido de despertar potencialidades muito significativas que os/as estudantes sequer sabiam que eram capazes de alcançar.

Como ponto de partida, recorri a Lecoq (2010, p. 69) ao dizer: "Quando o aluno sentir esse estado neutro do início, seu corpo estará disponível". Foi quando passei a experimentar uma aproximação entre o estado neutro (LECOQ, 2010) e o que Fabião (2010) chama de latência. Isto é, comecei a agir como provocador desde os primeiros encontros, para experienciar esse preenchimento energético no corpo ao se colocar em cena. Pontuo que, por meio do estado neutro (LECOQ, 2010), o corpo não está vazio nem abandonado, mas potente, latente.

Os primeiros exercícios (de se colocar no espaço e silenciar) apontaram um caminho libertador no sentido de que os formatos e pré concepções corporais dão espaço para o que se apresenta vivo naquele instante. Ali já há um princípio cênico, pois o/a estudante se coloca a frente dos/as colegas por meio desse estado. Por isso, o que Lecoq (2010) aponta como o "frescor da primeira vez" dialoga com o que Fabião descreve: 
Contra a ideia de corpos autônomos, rígidos e acabados, o corpo cênico se (in)define como campo e cambiante. Contra a noção de identidades definidas e definitivas, o corpocampo é performativo, dialógico, provisório. Contra a certeza das formas inteiras e fechadas, o corpo cênico dá a ver "corpo" como sistema relacional em estado de geração permanente (FABIÃO, 2010, p. 322).

Assim, no que concerne à receptividade que o corpo exige para se tornar preenchido, vivo, o exercício de voltar a atenção para o seu próprio corpo no espaço, e que age no instante em que o/a ator/atriz/bailarino/a pode permitir abertura do seu corpo para o novo. Sob esse pressuposto, Lecoq (2010) apresenta o silêncio e daí "só há dois meio de sair: a palavra ou a ação." (p. 58).

Estamos mais habituados a agir do que a distensionar, a ponto de sermos agidos; somos treinados para criar e executar movimento, não para ressoar impulso; geralmente sabemos ordenar e dar ordens ao corpo mais e melhor do que sabemos nos abrir e escutar. A busca por um corpo conectivo, atento e presente é justamente a busca por um corpo receptivo (FABIÃO, 2010, p. 323).

Foi então que passei a traçar um diálogo entre o silêncio, o estado de neutralidade (LECOQ, 2010), a latência, a receptividade (FABIÃO, 2010) e pensei em alguns exercícios introdutórios que pudessem trabalhar esses elementos na prática. Pedi aos/às estudantes durante as aulas que se levantassem e se colocassem se colocassem na postura inicial (figura 1).

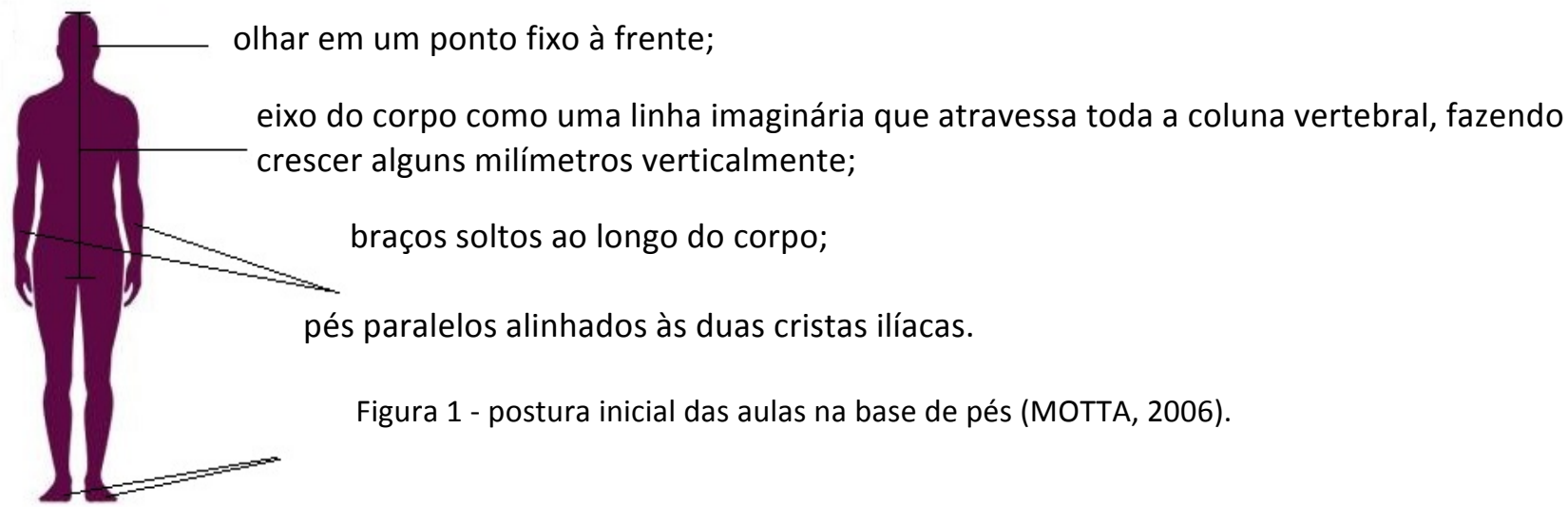

Essa passou a ser a estrutura do corpo - a qual chamei de postura inicial - em todas as aulas posteriores. A partir dessa base foi possível se pensar o trabalho artístico da anatomia para os desdobramentos dinâmicos usando o ritmo, a voz e a consciência desses corpos e suas propriedades, em diálogo com a prática docente desenvolvida no decorrer de todo o ano letivo. 
Com base nos conceitos mencionados, os exercícios começaram a ser aplicados superando diversos desafios. O primeiro deles foi o espaço. Exceto a quadra e o pátio da escola, todas as salas contém mesas e cadeiras. Para trabalhar com a ocupação mais proveitosa do espaço é importante deslocar a turma para os espaços vazios, ou tirar as mesas e cadeiras das salas. Porém, torna-se bastante ruidoso e disperso esses deslocamentos. Por isso, muitas vezes, opto em fazer os exercícios entre os móveis da própria sala. O segundo desafio é fazer com que o/a estudante perceba que esse corpo está sendo trabalhado sem achar que ali não há trabalho. Percebo isso, porque quase nenhuma das outras disciplinas do IE CIEP 179 pedem para levantar da cadeira, tampouco fazer uma roda e se colocar de pé (na postura supracitada). Só aí já há reações dos/as estudantes de estranhamento, risadas, comentários da necessidade de um entendimento racional sobre o que estão fazendo, que para muitos/as, aquilo seria "fazer nada" ou "só ficar parado/a". Porém, sempre pontuo essa gama de atravessamentos nesse exercício, a fim de criar o estado corporal de início, silêncio, latência. Esse silêncio que a neutralidade impõe é fundamental para que o corpo reconheça a si mesmo naquele dia, naquele instante, e que mesmo em um exercício aparentemente superficial há trabalho.

Em aulas posteriores, sugiro que olhem para o espaço escolar e tentem buscar ressignificar esse espaço, cada detalhe, cores, sinais, marcas, objetos, móveis e tudo que os/as envolve. Essa experiência gerou o que venho trabalhando junto aos/às estudantes: os diálogos entre os corpos mais cada uma das linguagens artísticas separadas nos 4 bimestres letivos, e que a partir de agora apresentarei separadamente.

\section{Corpos mais artes visuais}

O primeiro diálogo partiu de alguns conceitos fundamentais sobre a problematização do que é arte e suas possíveis interfaces com a própria vida. Para isso foram usados conceitos constantes no livro didático de Artes (UTUARI et al., 2013) do Ensino Médio fornecido pela SEEDUC/RJ. Nesse livro, os artistas inspiradores foram Marcel Duchamp e Paulo Bruscky. Como no livro existe a predominância de textos e fotografias, eu me dediquei a propor algo voltado também à fotografia como proposta prática com os/as estudantes. Do ponto de vista da utilização da fotografia, achei que seria possível, pois praticamente todos/as tinham celulares com câmera fotográfica. Aos/às que não tinham, sugeri pesquisas em duplas, desde que um/a deles/as tivesse 
celular com câmera. Foi então que as provocações e reflexões feitas pelos artistas estudados pressupunham um desdobramento criativo prático de ressignificação dos corpos na composição fotográfica.

Imbuídos da qualidade corporal a partir da base trabalhada anteriormente, a ideia da ressignificação dos corpos, de objetos e o espaço escolar cotidianos, iniciaram-se os processos. Comecei a perceber que alguns aspectos precisavam ser mais trabalhados para que as fotografias ganhassem qualidade artística. Ao mesmo tempo, para preservar os/as estudantes de possíveis postagens das fotos em redes sociais, vi que se eles/as não fotografassem seus rostos seria possível minimizar a identificação de cada um/a. Pontuei que haviam muitas maneiras de fotografar outras partes do corpo que não fossem o rosto de forma bastante interessante e com grande potencial artístico. Assim, o corpo e o espaço passaram a ser explorados de forma muito diferente das primeiras fotos que eram num formato recorrente ao que se encontra em redes sociais dos/as alunos/as.

Aliado a isso, comecei a provocá-los/as a prestarem atenção em alguns pontos que fariam bastante diferença na composição das fotografias, o que chamei de critérios de composição fotográfica. O enquadramento que diz respeito a tudo que aparece no retângulo da fotografia. A iluminação que corresponde à incidência (ou ausência) de luz sobre o que está enquadrado. A perspectiva a partir da profundidade advinda de pinturas do século XV (UTUARI et al., 2013). As cores, pois alguns filtros aplicados mexiam muito com a tonalidade e a saturação. E o contraste como algo marcante de diferença ou oposição entre elementos enquadrados nas fotografias.

Os critérios de composição fotográfica foram surgindo a partir de cada proposta e questionamento vindo das pesquisas, como: "essa árvore não era para aparecer"; "está muito escuro"; "a luz estourou"; "à luz natural do dia"; "ficou muito longe"; "deu ideia que eu estou segurando o sol"; "isso chamou muita atenção"; "foto só preto e branca" (como se as neutras não fossem cores); etc. Embora tenham sido critérios chamados por mim dessa forma, só depois comecei a estudar sobre eles e perceber que era bastante interessante esse caminho em uma formação de professores/as, pois estava sendo trabalhado um aprimoramento das qualidades estéticas, conforme a figura 2. Essas qualidades partiram de um olhar intuitivo para um olhar mais cuidadoso sobre as fotografias, assim como o uso da presença do corpo artístico/poético nessa relação entre a câmera e o espaço. 


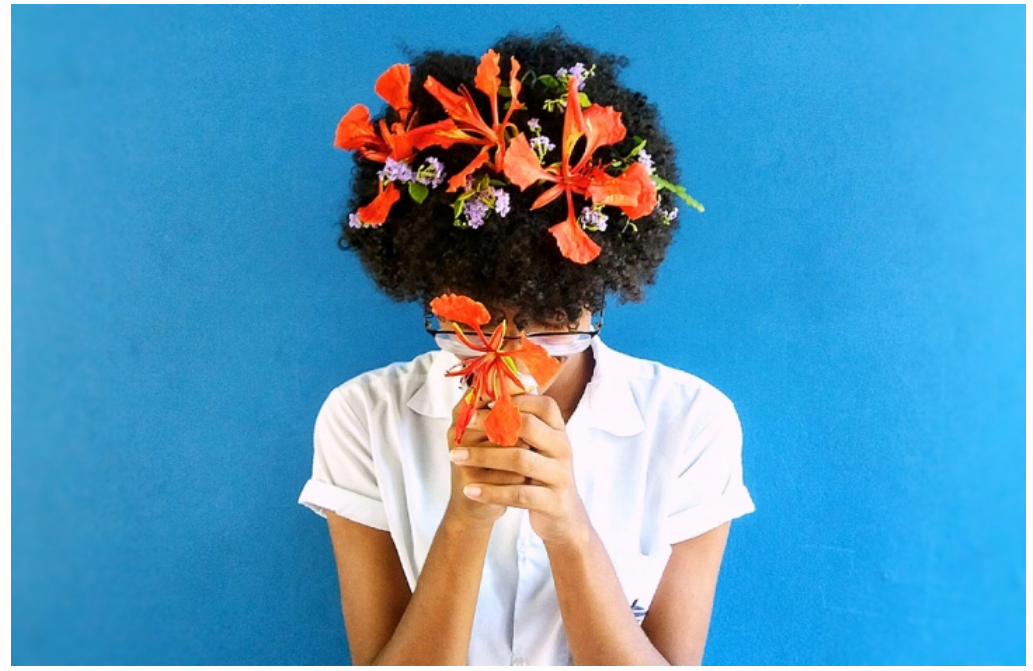

Figura 2 - processo de criação dos corpos mais artes visuais/2017 Fonte: Fotografia de uma aluna no processo

Ao final do trabalho, os relatos sobre os processos ultrapassaram discursos presos a "o/a professor/a precisa saber tirar bem fotos da escola e dos/as alunos/as" ou apenas "ter contato com a linguagem fotográfica", mas que mesmo em fotografias que não houvesse um conceito/ideia a se retratar, os critérios faziam diferença em não mais simplesmente tirar fotos de qualquer maneira. Passaram a ser pensados no quanto cada critério contribuía ou não para a ideia que se queria expor. Tudo que era visto e percebido pelo/a espectador/a poderia despertar diversas leituras, mesmo em casos em que o/a fotógrafo/a tivesse determinado propósito de mostrar.

\section{Corpos mais música}

Após essa gama de informações sobre o corpo, o espaço, e características de composições e leituras artísticas, no segundo bimestre o trabalho chega ao corpo com o enfoque musical. Mas a questão era: de qual forma essa música seria trabalhada? Foi então que pensei sobre esse corpo que experienciou se colocar no espaço, silenciar (LECOQ, 2010), se apropriar de aspectos da estaticidade na fotografia, pudesse, agora, ganhar dinâmicas a partir de células rítmicas. Resgatei alguns conceitos também vistos no livro de Artes (UTUARI et al., 2013), que podiam compreender a expansão do universo musical não apenas com instrumentos musicais convencionais. Comecei a 
falar que o uso do próprio corpo e materiais cotidianos, que não foram concebidos inicialmente para extrair música, poderiam ser muito potentes para a criação musical.

Para ampliar esses conceitos, principiamos a trabalhar com um tipo de método que obrigava o corpo a marcar o ritmo com os pés, palmas e, posteriormente, com outras formas de percussão corporal utilizando o "O Passo", que:

\begin{abstract}
é um método de Educação Musical criado por Lucas Ciavatta em 1996 e, atualmente, utilizado no Brasil e no Exterior. O Passo surge em resposta ao processo altamente seletivo do acesso à prática musical tanto nos espaços acadêmicos quanto nos espaços populares. Sua maior inspiração veio da riqueza do fazer musical popular brasileiro, principalmente no que diz respeito à relação corpo e música no processo de aquisição do suingue. Baseado num andar específico e orientado por quatro pilares (corpo, representação, grupo e cultura). O Passo introduziu no ensino-aprendizagem de ritmo e som novos conceitos, como posição e espaço musical, e novas ferramentas, como o andar que dá nome ao método, notações orais e corporais e a Partitura d'O Passo. 0 Passo não trabalha visando este ou aquele tipo de realização. Ele trabalha com a construção de uma base, algo que traz inúmeras possibilidades e abre uma porta, não apenas para os ritmos e os sons, mas para a rítmica como um todo e para uma real aproximação com o universo sonoro (CIAVATTA, 2009, p. 22).
\end{abstract}

Para Ciavatta (2009), a prática com "O Passo" se dá a partir de movimentos com os pés à frente e atrás (um passo e seu retorno) com um pé de cada vez, contando até quatro a cada pisada no chão. Conforme indicado na figura 3, para cada número entre parênteses ocorre a marcação de um passo. Começando com o pé direito, marcando os tempos: (1) pé direito à frente, (2) pé esquerdo alinhando ao anterior, (3) pé direito atrás, (4) pé esquerdo alinhando ao anterior; para números sem parênteses se bate uma palma; a cada sinal da letra " $\mathrm{e}$ ", bate-se o joelho da perna que se move para o próximo passo, marcando os contratempos.

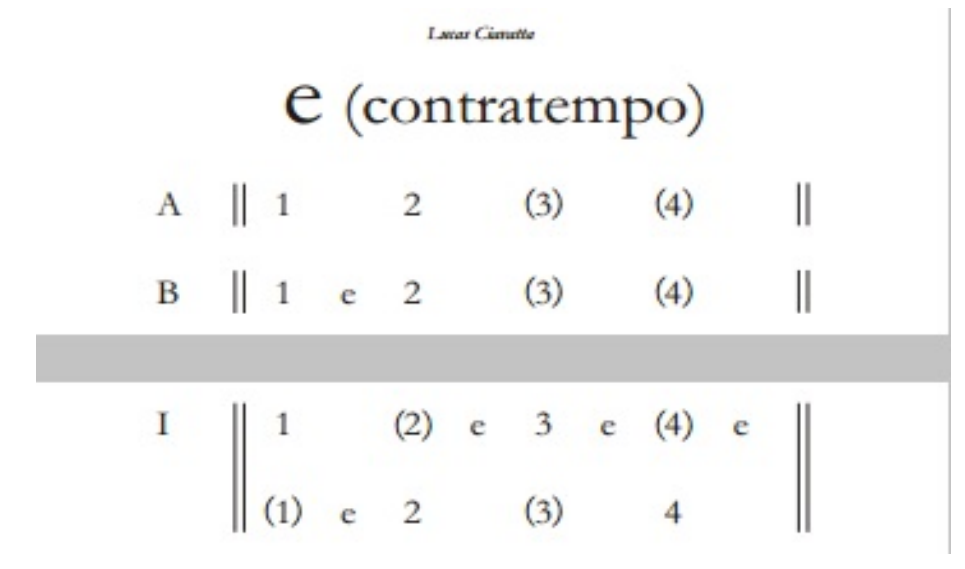

Figura 3 - Método "O Passo"

Fonte: Apostila do método "O Passo" de Lucas Ciavatta (2009). 
A partir dessas sequências, podem ser compostas as mais variadas frases rítmicas, utilizando diversos instrumentos, principalmente percussivos e a voz cantada ou falada. Inclusive iniciar a percepção sobre as noções do que seria pulso, compasso, tempo e contratempo em música, utilizando os próprios corpos.

Os processos práticos de experimentação se deram em grande parte pedindo a todos/as que levantassem, colocassem-se na postura inicial (figura 1), e iniciássemos o estudo d"O Passo". Eu mostrava primeiro cada sequência, depois fazíamos juntos e, por último, só os/as alunos/as. Na medida em que eu percebia dificuldades, eu tentava fazer na frente do/a estudante para que a lateralidade fosse visualizada com mais precisão. Pontuava também que se tratava de um processo que demandava de estudo, e que nem todos/as conseguiriam executar imediatamente. Sugeri ainda que as composições rítmicas fossem estudadas em grupos para criar integrações entre quem teve mais facilidade com quem não teve.

A exigência do estudo das sequências fez com que os corpos ganhassem mais atenção e ampliação das noções musicais a partir das experiências próprias, mas também percebendo a experiência nos outros corpos. Uma vez que há diversas formas de se estudar essas partituras, eles/as poderiam escolher a forma com a qual mais Ihe facilitaria o aprendizado. Observando o/a colega, ouvindo os diferentes sons de cada sequência, gravando ou filmando a sequência feita por ele/a mesmo/a, etc.

\section{Corpos mais teatro}

Dentre as inúmeras formas de se fazer teatro na escola, a escolhida partiu de alguns aspectos e autores que, na minha visão, pudessem integrar uma experiência interessante em uma formação de professores/as. Como o terceiro bimestre começa após o recesso do meio do ano letivo, houve a necessidade de retomar os conceitos e processos trabalhados anteriormente. Uma vez que já se tinha noção de experiências visuais/fotográficas e musicais/rítmicas, preferi expor as diferenças e especificidades que as artes cênicas têm.

Partimos, então, das bases que permeiam a teatralidade e suas possibilidades de criação e composição cênicas, tais como as ideias de catarse, performance, cenografia, indumentária, visagismo (UTUARI et al., 2013) e suas diferenças, principalmente com o que é mais familiar ao universo dos/as alunos/as do IE CIEP 179: a linguagem televisiva, cinematográfica e audiovisual. 
Todas essas informações foram tratadas de forma sucinta, até que se chegasse a uma questão que me pareceu bastante significativa, pois quando os/as estudantes imaginavam e falavam sobre teatro, eles/as recorriam, na maioria das vezes, ao uso da fala, da voz.

Embora tenha sido explicado sobre as possibilidades de se fazer teatro com a ausência da voz e/ou da fala, procurei problematizar conceitos que trouxesse mais entendimento, e que seriam possíveis de articular ao que já vinha sendo trabalhado anteriormente. Foi então que escolhi unir a esses corpos e suas experiências anteriores uma potencialidade vocal, pois também era uma grande questão: o quanto o/a professor/a utiliza a sua voz na prática docente?

A partir de exercícios baseados nas possibilidades da utilização vocal, começaram os processos práticos. Pedi que todos levantassem, retomassem a qualidade corporal do início do ano letivo (figura 1), e a partir da postura inicial comecei alguns exercícios vocais baseados em 3 blocos isolados e combinados: respiração, ressonância e articulação. Quase todas as aulas do bimestre eram repetidas essas sequências.

Foram pontuadas diferenças entre altura (grave $X$ agudo), intensidade/volume (alto $X$ baixo) e duração (lento $X$ rápido) a partir do controle da voz. Após isso, tivemos uma aula sobre sotaques de determinadas regiões do Brasil, e de características de pronúncias presentes em algumas línguas estrangeiras e suas utilizações para composições de personagens e cenas.

Finalizamos essa etapa com improvisações compondo personagens a partir da utilização da voz e da fala, com variações de alguns jogos (SPOLIN, 2000, BOAL, 2007, SUASSUNA, 1975 apud UTUARI et al., 2013) calcados em um trabalho que fosse integrado/integrante desses corpos.

\section{Corpos mais dança}

Na continuidade da proposta em que os corpos dos/as alunos/as experienciaram interfaces com a visualidade fotográfica, puderam ter noção do que seria um atravessamento rítmico e suas relações com a voz, chegou o quarto ponto da experimentação. Retornamos o trabalho com o espaço, mas com o olhar sobre a instrumentalização do conceito de kinesfera (LABAN, 1978) relacionado ao parâmetro forma (MOTTA, 2006). Para tanto, antes de explicar como se deu a metodologia de trabalho nas aulas, fez-se necessário apresentar os conceitos que foram abordados, e como eles estabeleceram essas relações. 
Um dos grandes desafios foi contraverter a lógica da dança presa somente a linhas estéticas ou técnicas específicas. Foi quando apresentei o termo dança livre (FREIRE, 2001) que possibilita emanar uma dança do próprio corpo sem pré-concepções. Isto é, o/a estudante do IE CIEP 179, que muitas vezes julgava seu comportamento corporal baseado em comparativos de padrões (bonito $X$ feio, certo $X$ errado, simétrico $X$ assimétrico, profano $X$ sagrado), pudesse começar a ter ideia de que menos importam técnicas e classificações, mas uma dança que os corpos livremente pudessem propor. A partir disso surgiram materiais potentes para a criação, desprovidos de pré-julgamentos.

Segundo Vianna (2005), “o corpo é a síntese da vida e a vida é a síntese do corpo". Isto é, se o desejo de dançar requisitar uma preocupação exterior, há uma grande chance da dança ficar refém de raciocínios pessoais, ou baseados na aceitação das pessoas que estão vendo. A dança livre (FREIRE, 2001) se incorporou ao processo de criação também com o propósito de explorar a característica que esses/as futuros/as professores/as possam desenvolver com alunos/as da Educação Infantil: a de movimentar o seu corpo de acordo com suas vontades. O que a criança quiser mover, ela moverá.

\footnotetext{
O que vemos, no entanto, é que o domínio da arte da dança, em nossos dias, obedece a certas regras e convenções em função de um ideal estético antecipadamente suposto e proposto. Mas é possível pensar a dança para além desses limites, como uma das raras atividades em que o ser humano se engaja plenamente [...] cada um de nós possui a sua dança e o seu movimento, original, singular e diferenciado, e é a partir daí que essa dança e esse movimento evoluem para uma forma de expressão em que a busca da individualidade possa ser entendida pela coletividade humana (VIANNA, 2005, p. 105).
}

Muitas vezes a dança livre (FREIRE, 2001) se confundia com a livre improvisação e experimentações sem nenhum propósito. Foi então que ofereci outro material como suporte para desdobramentos na prática da dança: o conceito de kinesfera (LABAN, 1978) a partir dos parâmetros espaço e forma (MOTTA, 2006) como inspiração para a criação em dança. O conceito de kinesfera (LABAN, 1978) representa os limites de ocupação do espaço de cada indivíduo baseado na geometria euclidiana, a partir de um ponto de apoio no centro do corpo, de onde podem emanar várias movimentações, como mostra a figura 4. 


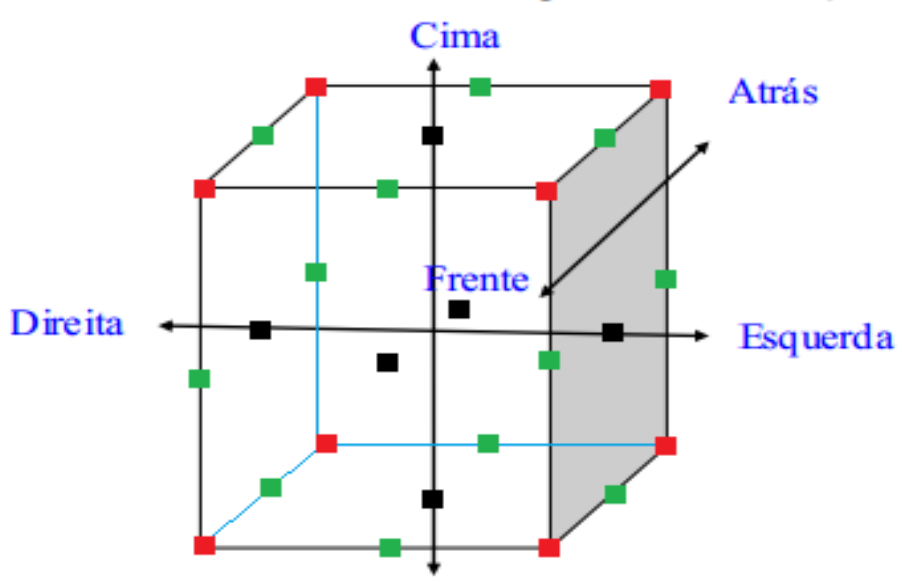

Baixo

Figura 4 - kinesfera de Rudolf Laban (1978) representada em formato de cubo para representação do conceito para os/as estudantes.

Fonte: Ilustração do autor.

A proposta se deu, a princípio, estendendo os membros superiores até alcançar a cada ponto marcado no cubo e criar movimentações a partir desses pontos. Além disso, o estudo dos parâmetros espaço e forma (MOTTA, 2006) serem trabalhados conjuntamente se dá devido à sua afinidade, e não são somente as perspectivas dimensionais e externas que entram em jogo, mas as suas relações intrínsecas. Com essa base, os/as alunos/as foram provocados/as a entender como seu corpo se relaciona no espaço de forma uni, bi e tridimensional. As possibilidades unidimensionais são: cima, baixo, frente, atrás, direita, esquerda. As bidimendionais (soma de duas unidimensionais) são: cima+frente, cima+atrás, cima+direita, cima+esquerda, frente+direita, frente+esquerda, atrás+direita, atrás+esquerda, baixo+frente, baixo+atrás, baixo+direita, baixo+esquerda. E as tridimensionais (soma de três unidimensionais) são: cima+frente+direita, cima+frente+esquerda, baixo+frente+direita, baixo+frente+esquerda, atrás+cima+direita, atrás+cima+esquerda, atrás+baixo+direita, atrás+baixo+esquerda.

Assim, as formas subjetivas deram lugar à experimentação em dança, e trouxeram um diálogo profundo com os conceitos trabalhados. Foram solicitadas que as experimentações se dessem de acordo com inspirações espaciais escolares. Por esse motivo, algumas construções coreográficas surgiram a partir de temas feitos em diferentes lugares da escola, unindo os conceitos aos movimentos corporais. 


\section{Conclusão}

A partir das narrativas consigo visualizar um ciclo, pois principiei com as ideias do que eu gostaria de propor e como os processos se desencadearam. Como professor de dança, o olhar sobre os corpos do IE CIEP 179 e as somas dos corpos mais também promoveram uma exploração artística de forma crescente. Ao passo que alguns conceitos e processos eram experienciados para um diálogo específico, outros eram aproveitados como desdobramentos por já terem sido experienciados. Isto é, visualizei um corpo que entendeu suas partes e articulações com o espaço na fotografia (estático), ganhou dinâmica a partir do rimo com o método "O Passo", reconheceu suas propriedades vocais em possíveis explorações cênicas, e finalizou com a tradução poética dos movimentos corporais no espaço.

Passei por indagações que me fizeram analisar esmiuçadamente cada um dos processos de trabalho e buscar o melhor proveito pelos/as estudantes do que vinha sendo abordado. Exercitei, sobretudo ao ouvir e perceber, o que precisava ser ajustado nos processos e suas aplicações aliadas a uma formação de professores/as. Portanto, retorno à premissa que norteia toda a minha pesquisa durante toda a minha pós-gradação: o quanto a prática dos corpos mais pode propiciar a criação de materiais, vocabulários e repertórios artísticos. Assim como o despertar de potencialidades criativas no sentido dos corpos carregarem em si grandes capacidades de exploração com seus/suas futuros/as alunos/as.

\section{Referências}

BRASIL. Ministério da Educação. Lei de Diretrizes e Bases da Educação Nacional, no 9.394/96, de 20/12/1996.

Parâmetros Curriculares Nacionais (PCNs). Brasília: MEC/SEF, 2000.

CLANDININ, D.; CONNELLY, F. Pesquisa narrativa: experiência e história em pesquisa qualitativa. Uberlândia: EDUFU, 2011.

CIAVATTA, L. O Passo: um passo sobre as bases de ritmo e som. Rio de Janeiro: 2009.

FABIÃO, E. Corpo cênico, estado cênico. Revista Contracorpos, v.10, n.3, set-dez 2010.

LABAN, R. Domínio do Movimento. São Paulo: Summus, 1978.

LECOQ, J. O Corpo Poético. São Paulo: Editora Senac, 2010. 
MOTTA, M. Teoria Fundamentos da Dança: uma abordagem epistemológica à luz da Teoria das Estranhezas. Dissertação de Mestrado. Niterói: UFF/IACS, 2006.

UTUARI, S.; LIBÂNEO, D.; SARDO, F.; FERRARI, P. Arte Por Toda Parte. Volume único. São Paulo: FTD, 2013.

VIANNA, K. A Dança. 7ạ edição. São Paulo: Summus, 2005.

Artigo submetido em 03/08/2019, e aceito em 09/10/2019. 